\title{
Influence of Inorganic Salts on the Adsorption of Cationically Modified Starch to Fibers
}

\author{
Nejc Zakrajšek \\ Minet.si d.o.o., Šentjakob 7, Ljubljana, Slovenia. \\ Email:nejc.zakrajsek@iam.si \\ Received October $7^{\text {th }}, 2013$; revised November $7^{\text {th }}$, 2013; accepted November $15^{\text {th }}, 2013$ \\ Copyright (C) 2014 Nejc Zakrajšek. This is an open access article distributed under the Creative Commons Attribution License, which \\ permits unrestricted use, distribution, and reproduction in any medium, provided the original work is properly cited. In accordance of \\ the Creative Commons Attribution License all Copyrights (C) 2014 are reserved for SCIRP and the owner of the intellectual property \\ Nejc Zakrajšek. All Copyright (C 2014 are guarded by law and by SCIRP as a guardian.
}

\section{ABSTRACT}

The article is focused on the influence of inorganic salts on the adsorption of cationically modified starch to fibers. Results show that low concentrations of inorganic salts usually affect the process of adsorption in a positive way. Adsorption efficiency at higher concentrations, however, depends on the type of inorganic salts as well as the sequence of adding inorganic salts and starch to paper suspension.

\section{KEYWORDS}

\section{Cationically Modified Starch; Adsorption; Inorganic Salts; Fiber}

\section{Introduction}

One specific characteristic of a paper suspension is its complex composition; it contains suspended particles as well as colloids and soluble substances. Different sizes and properties of particles influence the mechanism of particle retention. Larger particles with diameters or lengths exceeding $10 \mu \mathrm{m}$ are caught among pulp fibers during paper sheet formation on the paper machine wire. With smaller particles, however, the retention effect is decreased; retention is then mainly affected by interactions on the surface of the particle. Colloidal stability is the resistance of the colloidal dispersion before the process of agglomeration, i.e. flocculation. The stability of the colloidal suspension depends on both mutually attractive and repulsive forces among the particles and the frequency of interparticle collisions. Attractive and repulsive forces can be of different origins. Non-electrostatic attractive forces include the hydrogen bond, dispersive interactions, the covalent bond and Van der Waals forces. Electrostatic forces are either attractive in cases of oppositely charged particles, or repulsive if the surface of a particle has got the same charge. Non-electrostatic forces function is only with the particles being close enough, whereas the electrostatic forces are active even when the particles are wider apart. Attractive and repulsive forces existing be- tween two particles define potential energy as the function of the distance between the particles [1]. The energy of the interaction, consisting of the sum of attractive and repulsive forces, defines whether the binding of two particles will be successful or not. In addition to the distance between the particles, surface charge is important in polyelectrolyte binding as well. The electrostatic charge is accumulated on the surface of solid particles in paper suspension and represents the consequence of the disassociation of carboxylic groups, filler ionisation and substance adsorption to fiber surface [2]. Surface potential is defined by the type and surface density of charged groups. As a general rule, fibers, fines and fillers are negatively charged on the surface, which attracts oppositely charged ions and polyelectrolytes. Therefore, they become encircled by an electric double layer composed of a stationary layer of adsorbed ions (Stern layer) and a diffuse layer (Gouy layer) bordering on the solution's interior. The depletion of the electric double layer signifies a smaller potential difference causing a decrease in a particle's attraction in comparison with oppositely charged groups. During the depletion of the double layer, the critical concentration and charge of a cation are of significant importance. An increase in the valence of the cation improves its efficiency in the process of depleting the electric 
double layer $[3,4]$. The accumulation of components on the surface of another component is called adsorption. The process of adsorption can be affected by numerous factors, of which the most important are the specific surface of the adsorbent, the adsorbate's concentration and temperature level. The concentration of salts in paper stock is an important factor in the adsorption of polyelectrolytes such as cationically modified starch. In some cases, adsorption efficiency decreases together with an increasing concentration of salts, which shows that the attraction between the surface and the polyelectrolyte is mostly of electrostatic character. Cationic starch is one of the most important chemicals in the papermaking process [5], due to its relatively low price, renewable character, biodegradability and structural similarity to cellulose, which makes it a more suitable additive than synthetic preparations [6,7]. In addition, the application of cationic starch positively affects paper properties, which is the consequence of bond strengthening between fibers by means of a hydrogen bond between the free hydroxyl group on cationic starches and acidic groups on pulp fibers [8].

\section{Experimental Work}

In experiments, cationically modified corn starch with a $0.043-0.048$ substitution level was used. The solution of cationically modified starch was prepared in compliance with the manufacturer's recommendations and used within the following 6 hours. Adsorption was studied on sulfate hardwood fibers (Kotlas type). After refining $\left(29^{\circ} \mathrm{SR}\right)$, pulp suspension was further defibrated for 15 minutes at 3000 revolutions. After that, a suspension with dry substance concentration of $5 \mathrm{~g} / \mathrm{l}$ was prepared, followed by regular additions of $10 \mathrm{mg} / \mathrm{g}$ of cationically modified starch and different concentrations of inorganic salts to pulp. The influence of inorganic salts on the adsorption of cationically modified starch was investigated both in relation to the concentrations $\left(\mathrm{NaCl}, \mathrm{CaCl}_{2}\right.$ in $\left.\mathrm{AlCl}_{3}\right)$ and the sequence of substances (cationically modified starch, inorganic salt) added to suspension. The research into the adsorption of modified cationic starch to paper stock was conducted by using a Britt Jar. The base of this device is represented by a mixing jar in which pulp suspension is prepared and a screen with $100 \mu \mathrm{m}$ holes, located at the bottom of the jar. A mixer is fixed above the screen and prevents the formation of filtering layers of pulp on the screen. Such conditions provide for dynamic retention and at the same time prevent the influence of filtration effect on the adsorption. Tests took place at room temperature and with a mixing speed of $500 \mathrm{~min}^{-1}$. Conductivity was measured with the Tetracom 325 conductivity cell (WTW pH 537 pH-meter).

The quantitative determination of cationic starch in water was conducted in compliance with Tappi T419 om-02. Starch detection is based on the reaction of starch with I2-KI into a colored complex that can be detected on a spectrophotometer. Measurements were conducted on a UV/VIS Varian Cary 50 spectrophotometer at 580 nm wavelength. The amounts of adsorbed cationic starch on fibers and fines were calculated by means of the following equation:

$$
Y=\frac{V\left(C_{o}-C\right)}{m}
$$

where: $Y$ is the amount of adsorbed starch on fibers and fines $(\mathrm{mg} / \mathrm{g}), V$ is the volume of sample in the jar, $C_{o}$ $(\mathrm{mg} / \mathrm{l})$ and $C(\mathrm{mg} / \mathrm{l})$ are the concentrations of unadsorbed cationic starch at the beginning and at the end of the test, and $m$ is fiber mass (g).

\section{Results and Discussion}

In the first part of the experiment, inorganic salts were added to fibers, conductivity was tested and cationically modified starch was mixed in. Figure 1 shows the values of adsorbed cationically modified starch in dependence to salt concentrations expressed by conductivity. In closed circuits where $\mathrm{CaCO}_{3}$ is applied as filler, the usual conductivity values do not exceed $1 \mathrm{mS} / \mathrm{cm}$ [9]. Figure 1 indicates that the adsorbed amount of cationically modified starch changes together with conductivity. While remaining relatively constant in the range up to $3 \mathrm{mS} / \mathrm{cm}$, it mostly begins to decrease after that. A conductivity level exceeding $16 \mathrm{mS} / \mathrm{cm}$ visibly results in the adsorbed amount of cationically modified starch being decreased in the range of $10 \%$ to $80 \%$. Thus, salt concentrations (expressed as conductivity) below $3 \mathrm{mS} / \mathrm{cm}$ do not affect the adsorption of cationically modified starch, whereas above this value, the adsorbed amount changes according to the type of inorganic salt present. This is proved by Figure 2 showing that the amount of adsorbed cationic starch changes both with the concentration as well as the

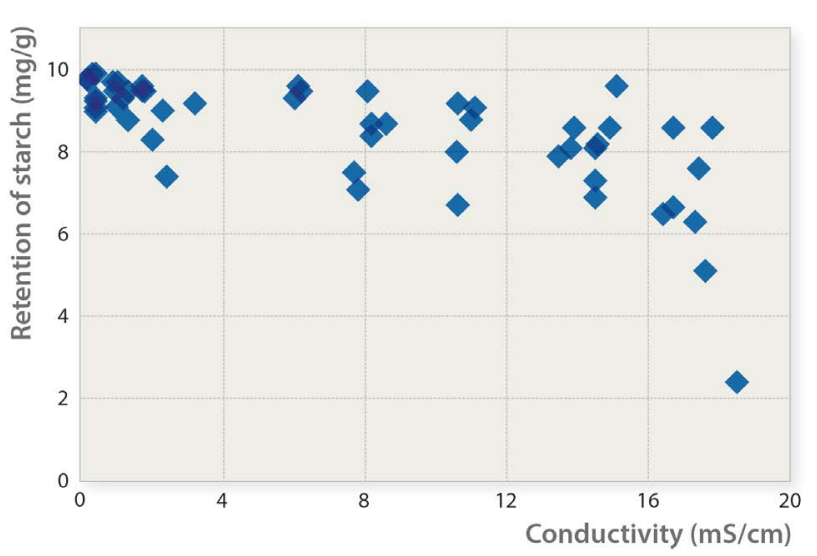

Figure 1. The mass of cationically modified starch retained per unit of fiber mass in dependence to salt concentration expressed by conductivity. 


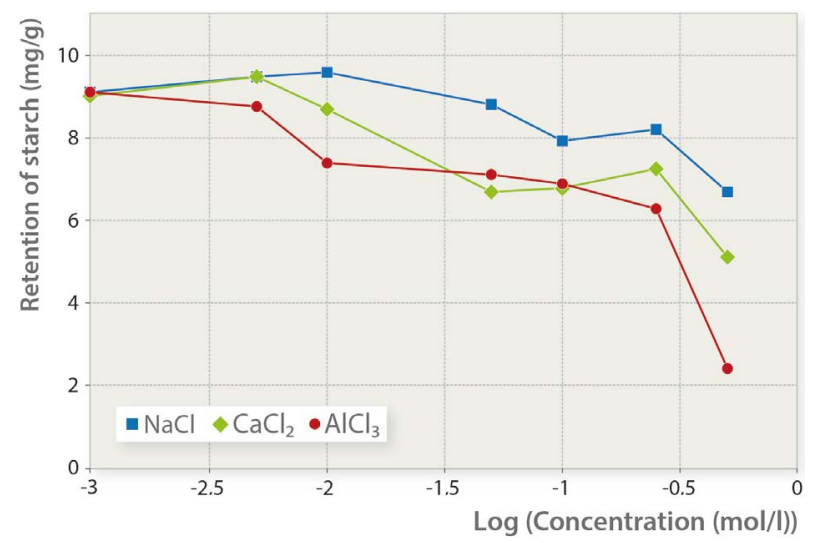

Figure 2. Mass of starch retained per mass unit of fibers in dependence to the logarithmic value of salts concentration.

type of added salts.

Added salts differ one from another according to cation size. As expected, a higher cation valence enhances the decrease in the amount of adsorbed starch. At the same time, higher salt concentration reduces adsorption efficiency, which indicates that adsorption is mostly dependent on electrostatic forces between the cationically modified starch and fiber surface [10]. It can thus be concluded that when $\mathrm{NaCl}$ in $\mathrm{CaCl}_{2}$ are added, the amount of adsorbed cationically modified starch even slightly increases if the salt concentration is increased as well. However, after reaching some point of critical concentration, it starts to decrease. In the case of adding $\mathrm{AlCl}_{3}$, the adsorbed amount was reduced already when smaller amounts of salts were added. To some extent, this contradicts certain research results whose author believes in the independence of the initial adsorption speed from salt concentration [11]. Some researchers believe that the increase of adsorbed amount in the presence of smaller concentrations of salts is caused by the fact that starch molecules are reduced and can thus penetrate through fiber pores [11-14]. Another group of researchers is sure that the reason for the increase is the reduced charge between individual segments on a polyelectrolyte. In adsorption, most of the segments of polyelectrolytes with charges significantly below 1 are quite far away from the surface, which repulses positive segments on a free polyelectrolyte within the solution. In cases of low salts concentrations the repulsion between the segments on the polyelectrolyte is reduced; consequently, the amount of adsorbed polyelectrolyte increases [15]. However, the authors seem to be unanimous that with higher concentrations of salts, cations are bound to negative spots on fibers and thus prevent the cationically modified starch to be adsorbed to them. Figure 2 shows that the adsorbed amount is decreased together with the concentration of inorganic salts. Such trend is typical for the adsorption processes of polyelectrolytes with mainly attractive forces of electrostatic nature.

In addition to an adequate $\mathrm{pH}$ value, temperature and mixing, a major factor that affects polyelectrolyte adsorption is the influence of the sequence in which chemicals are added. Case studies from various paper mills have shown that the efficiency of cationic starch adsorption can be reduced if cationic starch and other process chemicals are added at the same time [16]. In the second part of the experiment, thus, we conducted a research into both the sequence of adding inorganic salts and cationically modified starch, as well as the effect on adsorption efficiency.

The experiment was composed of three stages:

1) Inorganic salts in different concentrations were added to pulp first, whereas cationically modified starch was added after $20 \mathrm{~s}$ (Figure 3 ).

2) Cationically modified starch was added to pulp first, whereas inorganic salts in different concentrations were added 20 s later (Figure 4).

3) Both cationically modified starch and inorganic salts in different concentrations were added to pulp at the same time (Figure 5).

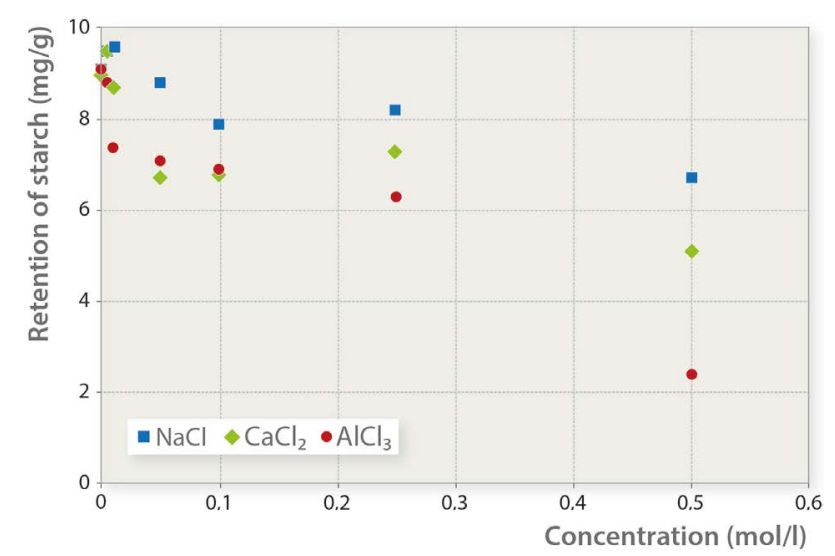

Figure 3. Mass of cationically modified starch retained per unit of fiber mass in dependence to salt concentration.

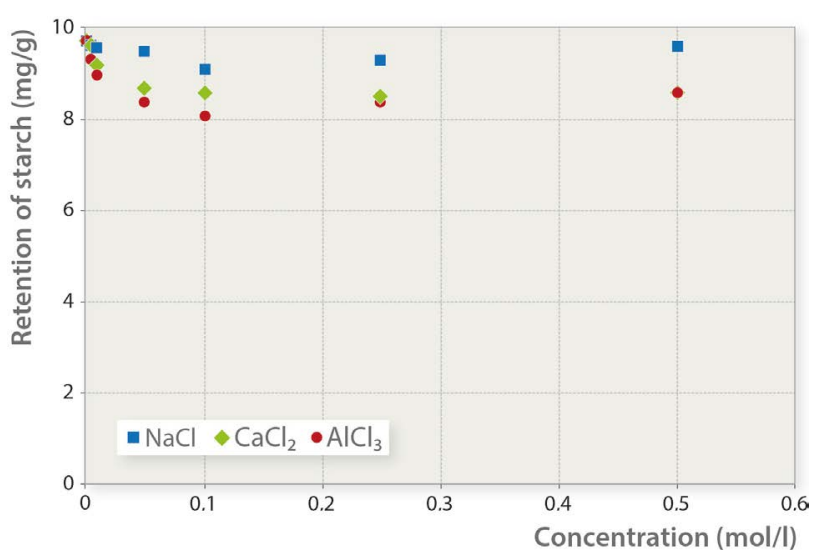

Figure 4. Mass of cationically modified starch retained per unit of fiber mass in dependence to salt concentration. 


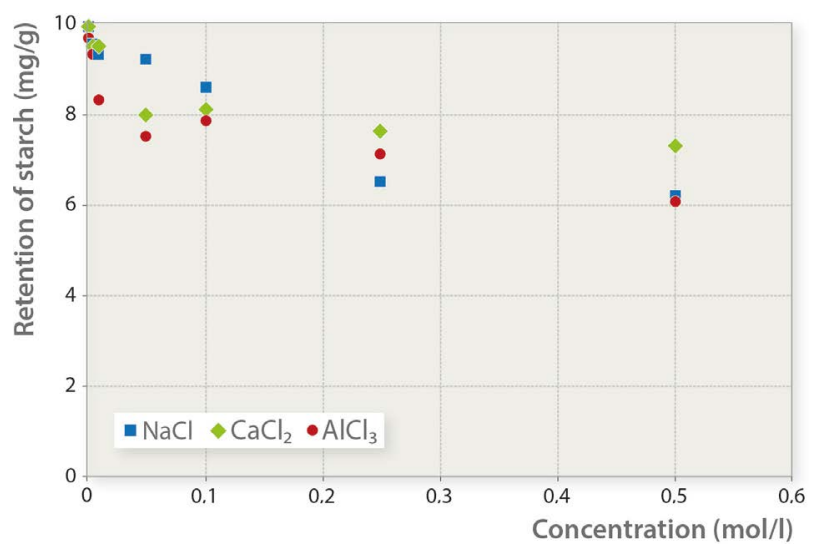

Figure 5. Mass of cationically modified starch retained per unit of fiber mass in dependence to salt concentration.

Figures 3-5 indicate that the sequence of adding inorganic salts and cationically modified starch is of key importance for adsorption to succeed. If inorganic salts are added to pulp before the cationically modified starch, the amount of adsorbed starch is reduced together with the cation size in inorganic salts. This is caused by the fact that the anion spots on fiber surface are occupied by the cation which results in the reduction of electrostatic attraction between fiber and cationically modified starch.

The influence of inorganic salts on adsorption is limited if cationically modified starch is added to paper stock before the inorganic salts and is given enough time to successfully adsorb to fibers. Inorganic salts were added $20 \mathrm{~s}$ after cationically modified starch. Therefore, they were added before the adsorbed amount is expected to reach the maximum level. The amount of adsorbed substance is reduced by mere $5 \%$ in the case of $\mathrm{NaCl}$, and $15 \%$ in cases of $\mathrm{CaCl}_{2}$ and $\mathrm{AlCl}_{3}$. The reduction of adsorbed amount can be attributed to the competition between the polyelectrolyte and the salt cations for free anion spots on fiber surface, and not to the desorption of already adsorbed layer since in such case, the amount of adsorbed cationically modified starch at higher concentrations of salts would be much smaller.

The competition for free anion spots is even more obvious if cationically modified starch and inorganic salt are added to paper stock at the same time. Figure 5 indicates that the level of polyelectrolyte adsorption with lower concentrations of inorganic salts is practically $100 \%$. When cation concentrations increase, they slowly begin to fill the free anion spots on fibers. Therefore, a larger amount of cationically modified starch remains in the solution. In such cases, the decrease in adsorption efficiency is relatively independent from the type of inorganic salt, implying that the frequency of collisions between fibers and cations or polycations bears far more importance than cation size. Due to its size and charge, cationically modified starch is thus in a favourable position in comparison with inorganic salt cations.

\section{Conclusion}

Electrostatic forces play an important role in the adsorption of polyelectrolytes to paper stock. In addition to the charges of fiber surface and polyelectrolytes, electrostatic forces are affected by the charges of other substances in the paper stock as well, i.e. inorganic salts formed from fillers and chemicals in process water. Inorganic salts influence the conductivity of the paper suspension as well. In the area where the inorganic salt concentration is expressed by conductivity below $3 \mathrm{mS} / \mathrm{cm}$, the influence on the adsorption is negligible. Conductivity is increased together with concentrations, whereas the amount of cationically modified starch decreases. If inorganic salts are previously added to suspension, the success of starch adsorption depends on the type of cation. The higher the cation charges in inorganic salt, the smaller the amounts of starch are adsorbed to fibers. Thus, it can be concluded that the adsorption of cationically modified starch to fibers depends mainly on electrostatic forces. In addition which is conducted at the same time, adsorption depends more on the frequency of collisions between fibers and cations or starch in suspension that on the type of cation.

\section{REFERENCES}

[1] J. Th. G. Overbeek, "Recent Developments in the Understanding of Colloid Stability," Journal of Colloid and Interface Science, Vol. 58, No. 2, 1977, pp. 408-422. http://dx.doi.org/10.1016/0021-9797(77)90151-5

[2] H. Eklund and T. Lindstrom, "Paper Chemistry: An Introduction,” DT Paper Science Publications, Grankulla, 1991.

[3] W. E. Scott, "Principle of Wet End Chemistry," Tappi Press, Atlanta, 1996.

[4] K. Sundenberg, J. Thornton, R. Ekman and B. Holmbom, "Interactions between Simple Electrolytes and Dissolved and Colloidal Substances in Mechanical Pulp," Nordic Pulp and Paper Research Journal, Vol. 9, No. 2, 1994, pp. 125-128.

http://dx.doi.org/10.3183/NPPRJ-1994-09-02-p125-128

[5] J. Marton, "Dry Strength Additives,” In: J. C. Roberts, Eds., Paper Chemistry, Blackie, Glasgow, London, 1992.

[6] C. P. Casey, "Pulp and Paper, Chemistry and Chemical Technology,” 3rd Edition, Vol. 3, John Wiley and Sons, New York, 1981.

[7] M. Cadotte, M.-E. Tellier, A. Blanco, E. Fuente and T. G. M. van de Ven, "Flocculation, Retention and Drainage in Papermaking: A Comparative Study of Polymeric Additives," The Canadian Journal of Chemical Engineering, Vol. 85, No. 2, 2007, pp. 148-152.

[8] G. J. Fleer, S. Cohem, J. M. H. M. Scheutjens, T. Cosgrove and B. Vincent, "Polymers at Interfaces," Chapman and Hall, New York, 1993. 
[9] V. Bobacka, J. Nasman and D. Eklund, "Interactions between Cationic Starch and Anion Trash of PeroxideBleached TMP at Different Salt Concntrations,” Journal of Pulp and Paper Science, Vol. 24, No. 3, 1998, pp. 78-81.

[10] F. Hedborg and T. Lindstrom, "Adsorption of Cationic Starch on Bleached Softwood Cellulosic Fibres," Nordic Pulp and Paper Research Journal, Vol. 8, No. 2, 1993, pp. 258-263.

http://dx.doi.org/10.3183/NPPRJ-1993-08-02-p258-263

[11] M. Shirazi, G. M. van de Ven and G. Garnier, "Adsorption of Modified Starches on Pulp Fibers," Langmuir, Vol. 19, No. 26, 2003, pp. 10835-10842. http://dx.doi.org/10.1021/la035064c

[12] T. Lindstrom, C. H. Baker and V. W. Punton, "Fundamentals of Papermaking: Transactions of the 9th Fundamental Research Symposium,” Mechanical Engineering Publications Limited, Cambridge, 1989.
[13] V. Bobacka, J. Nasman, N. Kreutzman and D. Eklund, "Adsorption of Cationic Starch onto Peroxide Bleached TMP Fibres: Influence of Interfering Wood Substances," Paperi Ja Puu-Paper and Timber, Vol. 81, No. 1, 1999, pp. 59-62.

[14] L. Wagberg, L. Odberg and T. J. Lindstrom, "Kinetics of Adsorption and Ion-Exchange Reactions during Adsorption of Cationic Polyelectrolytes onto Cellulosic Fibers," Colloid Interface Sci., Vol. 123, No. 1, 1988, p. 287.

[15] H. G. M. Van de Steeg, M. A. Cohen, A. de Keizer and B. Bijsterbosch, "Polyelectrolyte Adsorption: A Subtle Balance of Forces,” Langmuir, Vol. 8, No. 10, 1992, pp. 2538-2546. http://dx.doi.org/10.1021/la00046a030

[16] D. E. Boardman, "Some Practical Observations on the Use of Cationic Agents in the Control of Interfering Substances,” Tappi Journal, Vol. 76, No. 12, 1993, pp. 148152. 